Erratum to: Weigl, M., Müller, A., Hornung, S.,

Leidenberger, M., Heiden, B.: Job resources and

work engagement: the contributing role of selection, optimization, and compensation strategies at work

The Publisher

(C) Institut für Arbeitsmarkt- und Berufsforschung 2015

Erratum to: J Labour Market Res (2014) 47:299-312

DOI:10.1007/s12651-014-0163-4

The article mentioned above was submitted as part of the present Special Issue, but was inadvertently published in the last issue of volume 47. For completeness, it is reprinted here again as is.

We apologise for this oversight. 


\title{
Job resources and work engagement: the contributing role of selection, optimization, and compensation strategies at work
}

\author{
Matthias Weigl • Andreas Müller · Severin Hornung • \\ Max Leidenberger · Barbara Heiden
}

(C) Institut für Arbeitsmarkt- und Berufsforschung 2014

\begin{abstract}
The life-span model of selection, optimization, and compensation (SOC) provides a valuable theoretical framework for understanding organizational behaviour related to coping with age-related changes. Although previous research has demonstrated that SOC strategies at work contribute positively to individual outcomes, the role of workplace characteristics has been insufficiently addressed. This study investigated direct and indirect effects of SOC strategies at work and two important job resources (i.e., learning and developmental opportunities and autonomy at work) in predicting work engagement. All variables were assessed through employee self-reports based on standardized survey measures. Data collected from 118 flight attendants showed that SOC strategies were positively associated with work engagement $(r=0.28, p<0.05)$. Learning and developmental opportunities $(r=0.35, p<0.01)$ and job control $(r=0.31, p<0.01)$ were also related to work
\end{abstract}

This research was supported by the Munich Centre of Health Sciences (MCHealth). All authors declare that they have no conflict of interest. The study data was obtained as part of the master thesis requirements for Maximilian Leidenberger, University of Innsbruck, Austria.

M. Weigl $(\bowtie) \cdot$ B. Heiden

Institute and Outpatient Clinic for Occupational, Social, and Environmental Medicine, Medical Faculty, Ludwig-MaximiliansUniversity, Ziemssenstrasse 1,

80336 Munich, Germany

e-mail: matthias.weigl@med.lmu.de

\section{A. Müller}

Institute for Occupational Medicine and Social Medicine, Medical Faculty, Düsseldorf University,

Düsseldorf, Germany

S. Hornung $\cdot$ M. Leidenberger

Institute for Psychology, Leopold-Franzens-University, Innsbruck, Austria engagement. Additionally, we found meaningful mediation effects, such that positive associations of job resources with work engagement were significantly mediated through SOC use. These findings suggest that the application of successful aging strategies and enhanced job resources are conducive to engagement at work. Theoretical and practical implications regarding the joint effects of SOC strategies and job resources for successful aging in the workplace are discussed.

Keywords Age $\cdot$ Job control $\cdot$ Learning and developmental opportunities at work - Selection · Optimization · Compensation · Work engagement $\cdot$ Flight attendants

\section{Arbeitsressourcen und Arbeitsengagement: Der Einfluss von alternsgünstigen Handlungsstrategien der Selektion, Optimierung und Kompensation (SOK)}

Zusammenfassung Das Handlungsmodell der Selektion, Optimierung und Kompensation (SOK) hat sich als ein wichtiger Ansatz zum Verständnis der Bewältigung von alters- und alternsbedingten Veränderungen bei Beschäftigten an ihrem Arbeitsplatz herausgestellt. Bislang konnte die Forschung zeigen, dass Beschäftigte mit häufigen SOK-Strategien in der Arbeit erfolgreiches Altern am Arbeitsplatz berichten. Gleichwohl sind die verantwortlichen Arbeitsbedingungen für eine erfolgreichen SOK-Anwendung unzureichend beleuchtet. Unsere Studie untersuchte die direkten und indirekten Effekte für das Engagement in der Arbeit durch die Anwendung von SOK-Handlungsweisen am Arbeitsplatz sowie durch zwei zentrale Ressourcen der Arbeit: Lern- und Entwicklungsmöglichkeiten sowie Autonomie im Job. Diese Informationen wurden mittels 
eines Fragebogen erfasst, anhand standardisierter Skalen. Die Untersuchungsgruppe waren $N=118$ Flugbegleiter verschiedener deutscher und österreichischer Airlines. Die vermehrte Anwendung von SOK Strategien ging mit höherem Arbeitsengagement einher $(r=0.28, p<0.05)$. Lernund Entwicklungsmöglichkeiten in der Arbeit $(r=0.35$, $p<0.01)$ und Autonomie $(r=0.31, p<0.01)$ waren gleichfalls mit mehr Arbeitsengagement assoziiert. Anhand von Mediationsanalysen fanden wir, dass der positive Effekt der Arbeitsressourcen für das Engagement in der Arbeit durch die Anwendung von SOK Strategien teilweise vermittelt wurde. Unsere Ergebnisse demonstrieren, dass sowohl die Anwendung von alternsgünstigen Handlungsstrategien als auch die erweiterte Ressourcen der Arbeit positiv für das Engagement in der Arbeit sind. Der Beitrag schließt mit Empfehlungen für eine weitere theoretische Erforschung des Themas wie auch potentielle praktische Konsequenzen aus den Ergebnissen für eine alternsgünstige Arbeitsgestaltung.

Schlüsselwörter Alter $\cdot$ Autonomie $\cdot$ Lernen Entwicklungsmöglichkeiten · Selektion · Optimierung · Kompensation $\cdot$ Arbeitsengagement $\cdot$ Flugbegleiter

\section{Introduction}

The demographic changes of an aging workforce in western industrialized countries has stimulated increasing research on successful aging at work (Kanfer and Ackerman 2004; Shultz and Adams 2007; Baltes et al. 2012). Especially research approaches that stem from a life-span perspective have made substantial contributions (Schaie and Willis 2010; Lerner and Overton 2010). One particularly fruitful approach is the life-span model of selection, optimization, and compensation (SOC) (Baltes and Baltes 1990; Freund and Baltes 2002).

The SOC model posits that the coordinated use of certain behavioural strategies (a) increases access to resources in the sense of developmental enhancement, (b) helps to maintain functioning in the face of challenges, and (c) supports the regulation of impending resource losses (Baltes and Baltes 1990; Baltes and Lang 1997; Freund and Baltes 2002). It's core proposition is that aging individuals can manage their lives successfully through the synchronized use of three action strategies - selection, optimization, and compensation - which support the efficient and adaptive use of available resources (Baltes and Baltes 1990). The SOC model has received broad empirical support. Specifically, previous findings show that through the utilization of SOC strategies individuals maintain functioning, personal development, and well-being over the life-span, even in spite of dwindling personal resources (Riediger et al. 2006; Lang et al. 2011).
Our investigation examines flight attendants, whose work environment comprises many challenging and age sensitive work conditions like work overload, circadian rhythm disruption, emotional and customer-related stressors, high information load, and intense demands for the musculoskeletal system (Griffiths and Powell 2012; Grajewski et al. 2003). To inform occupational health interventions, further investigations are necessary to address the interplay of the work environment of flight crew personnel and factors that are beneficial to maintain well-being, performance, and capabilities (Griffiths and Powell 2012).

\section{Current state of research}

In regard to SOC at work, first research findings demonstrated that the SOC model can be generalized successfully to the workplace (Baltes and Dickson 2001). With regard to managing older workers, it offers a valuable theoretical framework for explaining organizational behaviour related to coping with age-related changes (Baltes and Dickson 2001; Baltes et al. 2012). Several studies provide support for the beneficial effects of the use of SOC strategies in work settings (Abraham and Hansson 1995; Bajor and Baltes 2003; Baltes and Heydens-Gahir 2003; Wiese et al. 2002; e.g., Zacher and Frese 2011). Employees who apply SOC strategies have been shown to report increased competency maintenance, career success, future opportunities at work, and improved job performance (Abraham and Hansson 1995; Bajor and Baltes 2003; Yeung and Fung 2009; Zacher and Frese 2011; Wiese et al. 2002).

With regard to aging workers, various studies suggest that especially older workers may benefit from the use of SOC strategies (Abraham and Hansson 1995; Yeung and Fung 2009; Zacher and Frese 2011; Müller et al. 2013b; Müller et al. 2012). Overall, results support the assumption that SOC strategies enable individuals to successfully cope with age-related changes and to counteract negative effects of age (e.g. physical decline, cognitive decrements). However, multiple studies in various professional contexts show that employees in general (i.e., irrespective of their age) benefit from the application of SOC at the job (e.g., Demerouti et al. 2014; Müller et al. 2013b; Schmitt et al. 2012; von Bonsdorff et al. 2014). Although the empirical evidence is inconsistent so far, it seems that the application of SOC strategies can be effective in dealing with diminished resources and in maintaining functioning also in comparatively younger employee cohorts (cf., Müller et al. 2013b).

Further, there is growing evidence that the effectiveness of SOC strategies at work partly depends on the nature and characteristics of the work environment (Müller et al. 2013b; Bajor and Baltes 2003). With regard to the nature of different work characteristics, recent studies revealed that 
particularly job resources, and, among these, especially job autonomy, are closely linked to the effectiveness of SOC strategies in the workplace (Müller et al. 2013b; Müller et al. 2012; Weigl et al. 2013). The surveys in hospital professionals revealed that increased job autonomy was associated with enhanced use of SOC strategies at the workplace. These investigations focused particularly on job resources because the availability of internal and external resources at work is relevant to coping with age-related changes at work. However, the knowledge-base on contextual determinants at work and their interplay with SOC strategies is limited and inconclusive and, therefore, in need of further theoretical and empirical elaboration (Riediger et al. 2006; Baltes and Dickson 2001; Müller et al. 2013b).

The current evidence base on the interplay of SOC behaviours in the workplace is inconsistent in determining whether SOC strategies function as a mediator or moderator in the relationship between characteristics of the job environment and individual outcomes (Müller et al. 2013b). Some authors argue that SOC behaviours act as a buffer for the relationship between job conditions and individual outcomes (moderator hypothesis) (Schmitt et al. 2012; Weigl et al. 2013; Zacher und Frese 2011). Accordingly, SOC is also supposed to function as a moderating variable, buffering the association between health and desirable individual outcomes, like good performance or intentions to remain in the job (Demerouti et al. 2014; Müller et al. 2013a). Nonetheless, there is empirical evidence which confirms that SOC behaviours may act as a mediator for the relationship between job conditions and well-being (mediator hypothesis): In one exemplary study in nursing professionals, SOC strategies were shown to be a meaningful mediator for the job control—work ability association (Müller et al. 2012). Recently, von Bonsdorff et al. confirmed this indirect effect in examining the association between organizational justice and work ability through SOC in Finnish hospital employees (von Bonsdorff et al. 2014). Consistent with this stream of research we argue that the availability, application, and effectiveness of SOC use is closely intertwined with the nature of the work environment (cf., Müller et al. 2013b). Thus, particularly job resources should stimulate behavioural strategies and their effective use in the workplace (please refer also to our justification for Hypothesis 4).

Against the background of these inconsistent findings, our study aims to elucidate the role of two important contextual resources at work-learning and developmental opportunities at work and job control-for the effectiveness of SOC strategies in the workplace. We argue that enhanced contextual resources at work stimulate SOC use and thus act as major source of work engagement. In that, we hypothesize that SOC strategies serve as an important regulatory instance, which is influenced by the working environment and, in turn, determines work engagement (e.g., Schaufeli und Bakker 2004).

Our study contributes to the literature on SOC at work particularly in two ways. First, investigations on contextual resources at work and the use of SOC strategies are so far scarce and mainly focus on the role of limited resources (cf., Riediger et al. 2006; Schmitt et al. 2012). Drawing on previous research, we seek to elucidate the role of enhanced contextual resources at work in facilitating the adaption and implementation of SOC strategies (Abraham und Hansson 1995; Hobfol and Wells 1998; Kanfer and Ackerman 2004).

Second, the majority of research on SOC strategies has examined white collar workers in managerial, highly educated professions, or senior hierarchical positions (Abraham and Hansson 1995; Bajor and Baltes 2003; Wiese et al. 2002; Young et al. 2007). This may cause problems of external validity since in white collar jobs, age-related losses may not be predominant enough to make SOC strategies highly relevant (cf., Abraham and Hansson 1995; Kanfer and Ackerman 2004). Thus, investigating SOC use in occupations with age-sensitive demands is important because such professions pose significant physical or psycho-motor demands which pose a substantial burden for individual capacities (Abraham and Hansson 1995). To this end, we studied flight attendants, whose in-flight work environment contains many age-sensitive job demands such as work overload, circadian rhythm disruption, high information load, and intense demands for the musculoskeletal system (Griffiths and Powell 2012).

Through investigating the joint impact of contextual job resources and SOC strategies, our research contributes to the growing evidence base on SOC behaviours and their role in maintaining well-being and capabilities of the workforce in age-sensitive jobs. The successful application of SOC strategies in age-sensitive work environments may be one of the potential contributing factors to promote worker well-being over the course of their professional careers.

\section{Theoretical backgrounds and hypothesis development}

\subsection{SOC: the model of selection, optimization, and compensation}

From a resource perspective (cf., Hobfoll 2001), dwindling personal (e.g., physical health) and contextual resources (e.g., access to training and promotion) of aging employees jointly outweigh potential resource gains (e.g., based on acquired work experience) (Baltes and Lang 1997). Thus, one of the core questions with regard to aging at work is how employees can maintain functioning, personal development, and well-being over the life-span despite a relative 
loss of resources (Baltes and Dickson 2001). According to theory, the synchronized use of SOC strategies supports successful aging through the focused allocation of available resources (Baltes and Baltes 1990).

Self-directed behaviours of selection, optimization, and compensation (SOC strategies) should enable individuals to effectively allocate and focus individual and external resources in the course of personal development (Baltes and Baltes 1990; Riediger et al. 2006). Drawing on an action regulation perspective, all three SOC strategies can be characterized as goal-related behaviours (Freund and Baltes 2002; Zacher and Frese 2011).

First, selection behaviours refer to goal setting and prioritization based on personal preferences (elective selection) or due to perceived loss of internal or contextual resources (loss-based selection). Thus, selection behaviours channel resources and prevent their inefficient dispersion across multiple goals. In regard to workplaces, workers aim to focus on preferred work objectives and abandon goals they are not capable to attain anymore (cf., Zacher and Frese 2011).

Optimization behaviours involve the obtainment and improved use of means to pursue selected goals. Specific optimization behaviours may include practicing, modelling others, and investing more effort or time into goal accomplishment (Freund and Baltes 2002). Employees use increased effort and persistence, though the tasks may be considered as difficult.

Compensation involves the acquisition and application of alternative individual means or use of external or technological support to maintain a desirable level of performance when previous means of goal attainment are no longer adequate in the face of actual or anticipated resource losses.

Our study is based on a conceptual framework of job resources, SOC strategy use, and work engagement (see Fig. 1). In the following we will develop our study hypotheses.

\subsection{Job resources and work-engagement}

Job resources are defined as physical, psychological, social, or organizational aspects of the work setting, which (a) are functional in achieving work goals; (b) reduce job demands and the associated physiological and psychological costs; (c) and/or stimulate personal growth, learning, and development (Bakker and Demerouti 2007; Demerouti et al. 2001; Schaufeli and Bakker 2004).

We focus on two important job resources, namely learning and developmental opportunities at work and job control. We define learning and developmental opportunities in the workplace as the possibility to advance skills and knowledge, to develop competencies, and obtain access to training and education in the organization. Particularly for aging

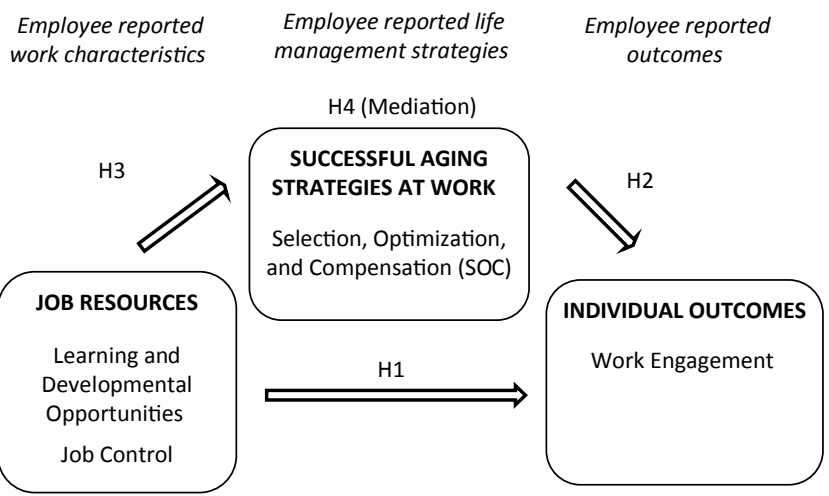

Fig. 1 Conceptual framework of job resources, SOC strategy use, and work engagement with study hypotheses $(\mathrm{H})$

employees, continuous learning and education are essential to maintain job-relevant skills and competencies (Maurer 2001). In managing older workers, organizations need to create work environments that offer and facilitate skill development and support employees to engage in learning and training activities (Kanfer and Ackerman 2004; Maurer 2001). Similarly, job control has been shown to be a central contextual resource at work. Consistent with Morgeson and Humphrey (2006), we define job control as the extent to which a job allows freedom, independence, and discretion in scheduling work, making work-related decisions, and choosing the methods to perform work tasks (see also, Wall et al. 1995; Terry and Jimmieson 1999; Hackman and Oldham 1976). A vast body of research has shown that job control is conducive to a broad range of desirable individual and organizational outcomes such as positive work experiences, job satisfaction, intrinsic motivation, and enhanced performance (e.g., de Lange et al. 2003; Fried and Ferris 1987; Saavedra and Kwun 2000; Humphrey et al. 2007; van der Doef and Maes 1999).

An individual work outcome that has recently attracted considerable research interest is psychological engagement. Work engagement is defined as a positive affective-cognitive state, characterized by vigour, dedication, and absorption (e.g., Schaufeli and Bakker 2004). This tripartite conceptualization is rooted in burnout research, reflecting positive antipodes to burnout dimensions of exhaustion, depersonalization, and inefficacy (Schaufeli and Bakker 2004). Engaged employees display high levels of energy, identify strongly with their jobs, and experience flow-like states at work. Notably, there is a robust association between work engagement and job performance (Christian et al. 2011).

Concerning the impact of job resources on work engagement, our assumptions draw on the job-demands resources model (JD-R), which states that contextual resources on the job are conducive to enhanced individual motivation or work engagement (Bakker and Demerouti 2007; Schaufeli and Bakker 2004; Demerouti et al. 2001). 
Hypothesis 1: Learning and developmental opportunities as well as job control at work are positively related to work engagement.

\subsection{Job resources, SOC strategies, and work engagement}

Previous research has emphasized the positive role and benefits of employees' SOC use on favourable individual outcomes like competence maintenance (Abraham and Hansson 1995), performance (Bajor and Baltes 2003; Yeung and Fung 2009), work ability (Müller et al. 2012; Weigl et al. 2013), focus on opportunities at work (Zacher and Frese 2011), and emotional well-being (Wiese et al. 2002). In regard to our study, we argue that employees who apply SOC strategies at work use their individual resources more efficiently and cope more effective with losses in individual functioning. SOC use helps employees to adapt to individual or environmental changes and allocate individual resources effectively, particularly in the face of dwindling individual resources, e.g., physical strengths, information processing (Riediger et al. 2006). This dynamic should result in enhanced well-being in the workplace, indicated by increased work engagement.

Hypothesis 2: SOC use is positively related to work engagement.

With regard to the association of job resources and SOC strategy use at work, we argue that enhanced contextual resources at work contribute to employees' SOC use. Concerning developmental and learning opportunities at work we assume that employees acquire skills and capabilities to cope with age-related demands at work. Particularly for aging employees, continuous learning and training is fundamental to maintain job-relevant skills and competencies (Maurer 2001). In regard to job control, we assume that the use of self-directed behaviour at work like SOC might benefit from enhanced job control. Greater job control in the workplace might enable employees to prioritize tasks (i.e., selection) or develop alternative approaches to carry out tasks (i.e., compensation) (Abraham and Hansson 1995). Findings of a recent study in nursing professionals provide first support for this assumption (Müller et al. 2012).

Hypothesis 3: Learning and developmental opportunities as well as job control at work are positively related to employees' SOC use.

Lastly, we hypothesize that the use of SOC at work mediates the relationship between learning and developmental opportunities/job control and work engagement, such that there will be a significant indirect effect of these job resources on work engagement through employees SOC use. Drawing on action theory that describes individual action regulation in the workplace, we argue that job resources at work affect individuals not until these conditions are internally represented in the job-incumbents (Frese and Zapf 1994; Hacker 2003). In regard to the job features under study, not only the mere presence of job resources should be relevant for work engagement, but the effective individual use of those job resources in terms of individual behaviour, i.e., SOC use. In regard to the interplay of job resources, SOC, and work engagement, SOC strategies are assumed to act as an intervening variable, mediating indirect effects of job resources on work engagement. Results from a previous investigation in nursing personnel provide preliminary support for this mediator hypothesis (Müller et al. 2012).

Hypothesis 4: SOC use at work mediates the relationship between learning and developmental opportunities at work respectively job control and work engagement, such as there is an indirect effect of the respective job resources on work engagement through SOC use.

\section{Method}

\subsection{Sample and procedure}

Data for this study were collected from May to June 2012 from flight crew personnel working in several German and Austrian airline corporations. It was assessed via an internetbased questionnaire as part of the master thesis of the fourth author, who was working as a part-time flight attendant with various flight crews. Participating flight attendants were contacted directly via mail. All recipients were also asked to promote this survey within their professional network.

For the sake of anonymity, names and specific information of the employing airlines were not collected. Attendants were informed about study aims, procedures, and confidentiality measures via e-mail and through the survey website prior to filling out the questionnaire.

Overall, $N=127$ flight attendants completed the online questionnaire (overall, the online questionnaire was activated by 210 visitors; however, not all completed the survey). $N=9$ data sets were removed from further analysis because respondents reported only socio-demographic information on page 1 and did not fill out further sections of the survey, which included the study variables. Complete information was obtained for $n=100$ data sets. $N=18$ data sets were subjected to imputation of missing values using the multiple imputation procedure. Finally, data of $N=118$ flight attendants were included in the analysis $(56.19 \%$ response rate).

In the survey sample, 77.1 per cent of the flight attendants were women $(N=92)$. Average age was 31.62 years 
$(S D=8.17)$ with a range from 20 to 57 years. Since we aimed to specifically include airline personnel from all age groups, we also tested for age variance within the sample. Age was normally distributed in the sample (Kolmogorov-Smirnov $Z=1.23 ; p=.08)$. The average job tenure of flight attendants in their current employment was 6.11 years $(S D=6.02$, Range $0.1-30$ years). Participants' age was highly correlated with job tenure $(r=.70, p<.01)$. With regard to education, the largest proportion reported secondary school graduation ('Abitur/Matura', $N=59,50.0 \%$ ), followed by university degree ('Diploma', $N=26,22.0 \%$ ), and General Certificate of Secondary Education ('mittlere Reife', $N=14$, $11.9 \%)$. 69 respondents were working full-time $(58.5 \%)$, and 7 participants held a supervisory position (5.9\%).

\subsection{Measures}

Job resources Learning and developmental opportunities in the organization was assessed with a four items scale from the learning culture inventory in organizations (LKI) developed by Sonntag and colleagues (Sonntag and Stegmaier 2008). Sample items are „The organization offers a large program for advanced education", and "Opportunities for further training and competency development are tailored to the needs of us employees". Job control was measured with six items from the Work Design Questionnaire (WDQ) originally developed by Morgeson and Humphrey (2006). We used items from the German WDQ (Stegmann et al. 2010). To obtain a score for the overall extent of autonomy and control at work, we combined the sub-scales for work scheduling autonomy and decision making authority. Sample items are "the job allows me to make my own decisions about how to schedule my work", "the job allows me to plan how I do my work", "the job gives me a chance to use my personal initiative or judgment in carrying out my work", and "the job allows me to make a lot of decisions on my own". Response format for all two scales ranged from 1 "no, not at all" to 5 "yes, very much".

Use of SOC strategies. Employees' selection, optimization, and compensation strategies (SOC) were assessed with the German version of the 12-item scale by Paul Baltes and colleagues (Baltes et al. 1999; cf., Freund and Baltes 2002). The questionnaire operationalizes the processes of adaptive development proposed in the SOC model, i.e. selection (6 items), optimization ( 3 items), and compensation ( 3 items) behaviours. The SOC model conceptualizes SOC strategies as an overall orchestrated, synchronized ensemble of behaviours, rather than focusing on the application of single SOC components (Baltes and Baltes 1990; Lang et al. 2011). Therefore, to investigate and measure SOC strategies, the use of a composite score of all three components is recommended (Freund and Baltes 2002; Jop and Smith 2006). This also applies to the measurement of SOC strate- gies at work (Zacher and Frese 2011; Baltes and HeydensGahir 2003). In the original SOC scale each item consists of two alternative statements, one referring to SOC- and one to a non-SOC strategy; participants are instructed to decide, which of the alternatives fit their behaviour better (Baltes et al. 1999; cf., Freund and Baltes 2002). In the present study, we used the revised response scale developed by Zacher and colleagues (Zacher and Frese 2011; Zacher et al. 2010). To reduce cognitive complexity and potential item ambiguity, the revised version is based on a 5-point Likert format to assess the extent to which respondents apply SOC strategies at work ( $1=$ "no, not all", $5=$ "yes, very much"). Sample items for the selection behaviours are "I concentrate all my energy on few things", and "I always focus on the one most important goal at a given time"; "I make every effort to achieve a given goal" and "If something matters to me, I devote myself fully and completely to it" indicate optimization behaviours; two sample items of the compensation dimension are "When things don't go as well as they used to, I keep trying other ways until I can achieve the same result I used to" and "When something in my life isn't working as well as it used to, I ask others for help or advice".

Work Engagement. Work Engagement was measured using the German 9-item short version of the widely used Utrecht Work Engagement Scale (UWES-9) developed by Schaufeli and Bakker (2003). The three sub dimensions of vigour, dedication, and absorption are each represented by three items (e.g., "At my job, I feel strong and vigorous"; "I am enthusiastic about my job"; and "I feel happy when I work intensely"). Flight attendants rated how often they experienced these positive work-related states, using a 7-point scale from 1 = "never" to $7=$ "always/every day".

Control variables. Information on flight attendants' gen$\operatorname{der}(1=$ female, $2=$ male), age (in years), and leadership or supervisory position $(1=$ no, $2=$ yes, e.g., chief flight attendant, purser) were based on employee self-reports. Additionally, attendants' prior education and qualification as well as working time ( 1 = full time, $2=$ part time contract $)$ were considered.

\subsection{Statistical analyses}

After double-checking the data for outliers and incorrect values, confirmatory analyses were carried out to test the pre-defined structure of our measures and to test our measurement model (Anderson and Gerbing 1988). Confirmatory factor analysis (CFA) was used to establish the factorial validity of the scales (AMOS 20.0; maximum-likelihood estimation). We examined accepted goodness-of-fit indices and applied conventional cut-offs (e.g., Byrne 2001; Brown 2006). Relative chi-square ( $\chi^{2} / \mathrm{df}$ ) should not exceed values of 2.0; incremental fit indices (incremental fit index, IFI; Tucker Lewis index, TLI; comparative fit index; CFI) 
Table 1 Discriminant validity results and goodness-of-fit Indices for study scales

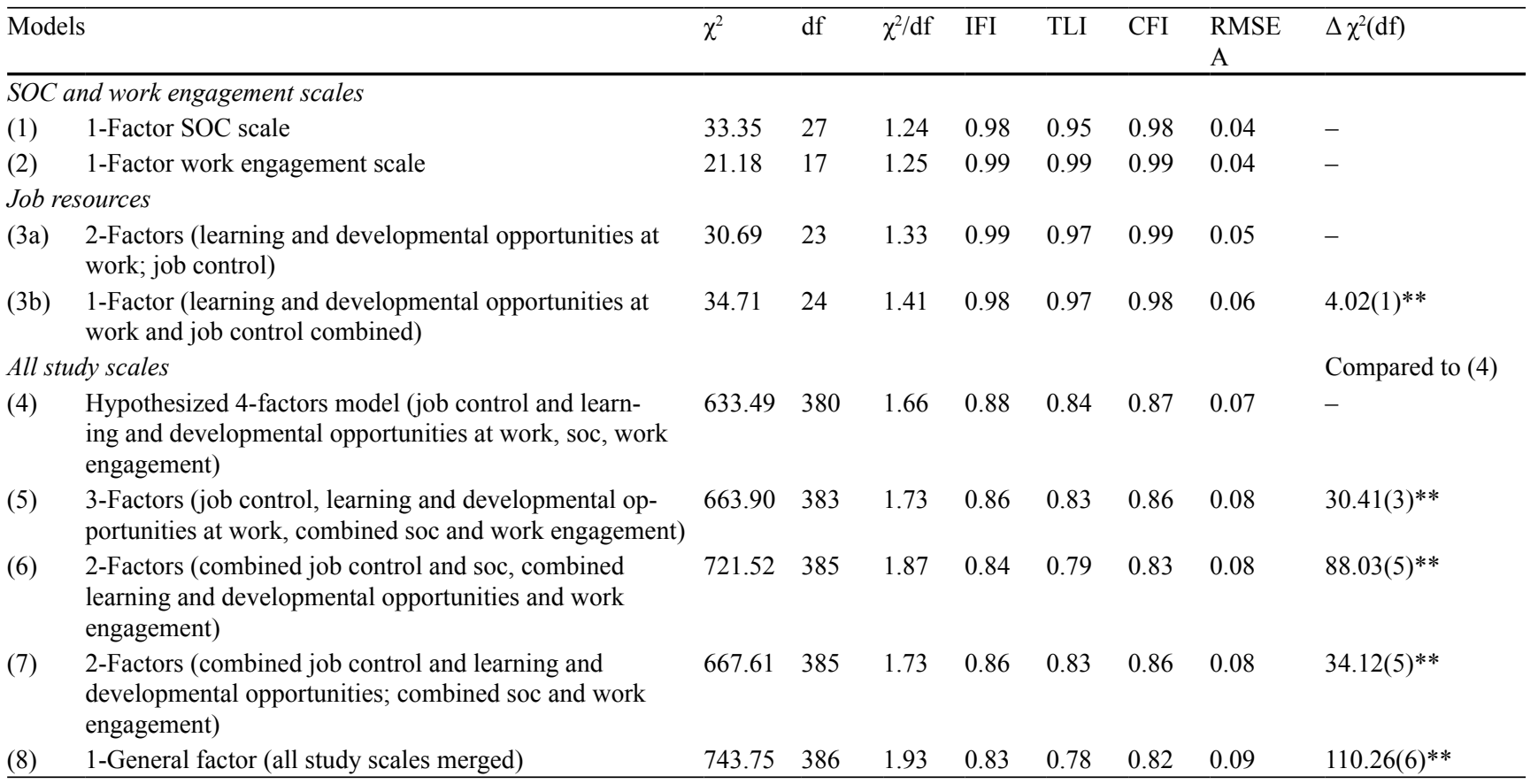

$N=118$

$* p<0.05, * * p<0.01$

should be $>0.90$; a root mean square error of approximation (RMSEA) $<0.05$ indicates good and $<0.07$ satisfactory fit. Model comparisons used $\chi^{2}$ statistics. The sub-structure of the SOC scale and the job control scale were modelled by correlating the measurement errors of items within each of the sub-dimensions (Brown 2006).

Given the strong fit of our measurement model, we used mean aggregates for each variable in subsequent analyses (Anderson and Gerbing 1988). To account for missing values we used 10 different simulated data sets for hypothesis testing that were completed with multiple imputation (Rubin 1987). Multiple imputation has been shown to produce unbiased parameter estimates for missing data (Schafer and Graham 2002). Mediated regression analyses were conducted for each job resource separately, i.e., job control and learning and developmental opportunities at work. To examine the hypothesized mediation effects, the approach propagated by Preacher and Hayes was applied (Preacher and Hayes 2008). First, all main effects (Hypotheses 1-3) and subsequently, the indirect (mediator) effects were computed (Hypothesis 4). Mediation was formally tested with bootstrapped estimates of the indirect effect of job control (respectively learning and developmental opportunities) on work engagement through SOC. This approach was chosen because bootstrapped estimates are robust against violations of the normal distribution of variables (Shrout and Bolger 2002). Covariates (i.e., gender, age, and leadership position) were controlled for in testing the associations between the independent variable and the mediator and between the mediator and the dependent variable. All imputations and analyses were performed with SPSS 22.0.

\subsection{Scale analyses}

Prior to the main analysis, the factorial validity of the scales was established using CFA. Goodness-of-fit indices are provided in Table 1. First, we tested a 1-factor model of SOC strategy use. The theoretical sub-structure of selection, optimization and compensation behaviours was modelled by correlating the measurement errors of items within each of the sub-dimensions (Brown 2006). Similarly, we tested in the next step a 1-factor model of work engagement. Both resulting measurement models displayed close fit to the data (cf., Table 1). Next, we tested a 2-factor model consisting of learning and developmental opportunities at work and job control scales, in which the sub-structure of both scales was modelled similarly, i.e., correlating the item measurement errors within sub-scales (Weigl et al. 2013). Again, model fit was satisfactory, also in contrast to the 1-factor model in which we merged both job resources scales (step $3 b$ ). Subsequently, in step 4, we tested the hypothesized 4-factor model of learning and developmental opportunities, job control, SOC use, and work engagement. The resulting indices showed satisfactory psychometric properties. To further test the factorial distinctness of the hypothesized model, we compared the complete measurement model to four alternative models: a 3-factor model, which subsumed the SOC and work engagement scale under a common factor (step 5); 
Table 2 Means (M), standard deviations (SD), and inter-correlations of study variables

\begin{tabular}{|c|c|c|c|c|c|c|c|c|c|c|c|}
\hline \multicolumn{2}{|c|}{ Study variables } & \multirow{2}{*}{$\begin{array}{l}\mathrm{M} \\
1.23\end{array}$} & \multirow{2}{*}{$\begin{array}{ll}\text { SD } \\
0.42\end{array}$} & \multirow{2}{*}{$\frac{\text { Range }}{1-2}$} & \multirow[t]{2}{*}{1} & \multirow[t]{2}{*}{2} & \multirow[t]{2}{*}{3} & \multirow[t]{2}{*}{4} & \multirow[t]{2}{*}{5} & \multirow[t]{2}{*}{6} & \multirow[t]{2}{*}{7} \\
\hline$\overline{1}$ & Gender & & & & & & & & & & \\
\hline 2 & Age (years) & 31.62 & 8.17 & $20-57$ & -0.01 & & & & & & \\
\hline 3 & Leadership position & 1.06 & 0.24 & $1-2$ & 0.12 & 0.15 & & & & & \\
\hline 4 & $\begin{array}{l}\text { Learning and developmental } \\
\text { opportunities }\end{array}$ & 3.40 & 0.78 & $1-5$ & 0.14 & -0.10 & 0.01 & $(0.81)$ & & & \\
\hline 5 & Job control & 2.78 & 0.67 & $1-4.3$ & 0.17 & 0.03 & $0.29 * *$ & $0.51 * *$ & $(0.83)$ & & \\
\hline 6 & SOC strategies & 3.27 & 0.45 & $1.42-4.58$ & 0.10 & -0.03 & -0.06 & $0.35 * *$ & $0.22 *$ & $(0.75)$ & \\
\hline 7 & Work engagement & 4.76 & 1.09 & $1.22-7.00$ & 0.06 & 0.07 & -0.05 & $0.35^{* *}$ & $0.31 * *$ & $0.28 *$ & $(0.94)$ \\
\hline
\end{tabular}

$N=118$; Scale reliabilities (Cronbach's Alpha) are displayed in parentheses on the table's diagonal; For gender, $1=$ female, $2=$ male; For leadership position, $1=$ no, $2=$ yes

${ }^{*} p<0.05,{ }^{*} p<0.01$, two-tailed

two 2-factor models, which systematically subsumed two of the four scales under one factor (steps 6 and 7); and one general 1-factor model (step 8). None of the four alternative models attained comparatively satisfactory fit and all had a significantly higher $\chi^{2}$ discrepancy than the theoretical 4-factor model (see Table 1). Accordingly, the hypothesized factor structure was fully supported.

\section{Results}

\subsection{Correlational and regression results}

Pooled descriptive statistics and inter-correlations of variables under study are shown in Table 2 . With regard to socio-demographic control variables, we found no effect for gender and age. Employees in leadership position reported enhanced job control $(r=0.29, p<0.01)$. SOC strategy use was positively associated with learning and developmental opportunities $(r=0.35, p<0.01)$ and job control $(r=0.22$, $p<0.05)$. Reported work engagement was positively related to learning and developmental opportunities $(r=0.35$, $p<0.01)$, to job control $(r=0.31, p<0.01)$, as well as to employees' SOC strategy use $(r=0.28, p<0.05)$.

The results of the individual mediated regression analyses are summarized in Table 3. All effects were estimated controlling for gender, age, and leadership position (associations for control variables are not reported).

First, we investigated the direct effects in the interplay of job control, SOC strategy use (mediator), and work engagement. Job control was positively associated with work engagement (Hypothesis 1) as well as with SOC use (Hypothesis 2). Also, a positive association of SOC strategies on work engagement (Hypothesis 3) was observed (cf., Table 3). Additionally, in line with Hypothesis 4 we found a significant indirect effect of job control on work engagement mediated through employees' SOC strategy use ( $B=0.09,95 \% \mathrm{CI} 0.02-0.22$ ). The direct effect of job control on work engagement remained significant under control of the mediator SOC $(B=0.50, S E=0.16, t=3.03, p<0.01)$, indicating a partial mediation effect. Thus, there are some effects of job control on work engagement that cannot be explained by the mediation of SOC strategy use.

Secondly, we investigated the interplay of learning and developmental opportunities, SOC strategy use, and work engagement. All hypothesized effects were significant (cf., Table 3): there was a significant association between learning and developmental opportunities and work engagement (H1) and SOC use (H2), as well as a significant positive relationship of SOC use and work engagement (H3). To investigate Hypothesis 4, mediation analysis revealed a significant indirect effect of learning and developmental opportunities on work engagement mediated via employees' SOC strategy use $(B=0.09,95 \%$ CI0.02-0.22). Since the direct effect of learning and developmental opportunities on work engagement remained significant $(B=0.41, S E=0.12$, $t=3.32, p<0.01)$, this constellation also indicates partial mediation.

To test the robustness of our results, we conducted additional mediation analyses and added further information on socio-demographic characteristics, i.e. working time (full- vs. part-time contract) and education. In regard to education, we aggregated the information into two categories: first, secondary or high school degree or completion of professional training, $N=92$ (78\%); secondly, academic/ university degree $N=26$. The results remained consistent after controlling for working time and education: we observed significant indirect effects of job control $(B=0.09$, $S E=0.05$, CI0.01-0.22, $\left.R^{2}=0.21, p<0.01\right)$ and learning and development opportunities $(B=0.09, S E=0.05$, CI0.01$\left.0.23, R^{2}=0.23, p<0.01\right)$ through SOC on work engagement.

Taking into account that there is some empirical evidence that especially older workers benefit from the use of SOC strategies, we ran an additional analysis to test the influence of employees' age. We thus checked if the strength of the indirect effect of job resources through SOC on work engagement depends on the effects of age, i.e. the path of SOC on work engagement is moderated by age (moder- 
ated mediation-model). For this purpose we ran an analysis approach developed by Preacher and colleagues and changed employees' age to a moderating variable (Preacher et al. 2007). Control variables were gender and supervisor position. We did not find a significant moderating impact of age for the indirect effect of the two job resources on SOC and work engagement; neither for job control $(B=0.01$, $S E=0.03, t=0.14, p=0.89)$ nor learning and developmental opportunities $(B=0.01, S E=0.03, t=0.22, p=0.83)$.

\section{Discussion}

SOC strategies for successful aging are critical for the active allocation of personal resources to work tasks. This investigation aimed to elucidate the interplay between job resources and individual life management strategies of 'successful aging' in terms of selection, optimization, and compensation in determining work engagement. Drawing on a sample of flight attendants, our study revealed a meaningful indirect effect of job control, respectively learning and developmental opportunities, on work engagement mediated through employees SOC use. Our study findings contribute to the evidence base on job resources, SOC use, and work engagement in various aspects:

First, the most novel finding of our research is that employees' SOC strategies act as a meaningful mediator between contextual resources in the work environment and individual engagement at work. Observed mediation effects deliver insights into the processes through which job resources might affect individual work engagement. Hence, our study contributes to the growing evidence base on the dynamic interplay of job characteristics, SOC use, and individual outcomes at work (Müller et al. 2012; Zacher and Frese 2011; Weigl et al. 2013; von Bonsdorff et al. 2014). Our findings are consistent to another study among nursing professionals, showing that SOC strategies act as a meaningful mediator between job control and work ability (Müller et al. 2012). Further, our results extend the findings of Müller et al. (2012) by demonstrating that other job resources also contribute indirectly to favourable individual outcomes through SOC use: In addition to job control, learning and developmental opportunities determine successful individual functioning at work through enhanced life-management strategies. Since the findings of Müller et al. (2012) were based on nursing professionals, our results in flight attendants provide further validity for the mediating role of SOC behaviours in another age-sensitive occupational domain.

However, the evidence base on SOC use at work is still inconsistent in establishing the mediating or moderating role of SOC behaviours in the relationship of job characteristics and individual outcomes. We hypothesized that $\mathrm{SOC}$ act as a mediator and found empirical confirmation within the surveyed sample (mediation hypothesis, see Fig. 1). This is consistent to previous research that proposes that SOC behaviours mediate the relationship between job control and work ability (Müller et al. 2012). Notwithstanding, there is evidence that employees' SOC use may also act as meaningful buffer for the relationship between job conditions and individual outcomes (moderator hypothesis). Empirical support for the moderating role of SOC was found for the relationship between problem-solving demands and job-related well-being (Schmitt et al. 2012), job control and work ability (Weigl et al. 2013), organizational justice and work ability (von Bonsdorff et al. 2014), as well as between job complexity and employees' focus on future opportunities (Zacher and Frese 2011). Recent studies revealed a meaningful buffering effect of SOC strategy use on the burnout and performance relationship (Demerouti et al. 2014) as well as for the association between employee health and intention to remain in the profession (Müller et al. 2013a).

Second, our study contributes to the growing evidence base on the benefits of SOC use at work. To the best of our knowledge, our study is the first to establish a direct relationship between SOC behaviours and work engagement. Hence, our study suggests that employees who apply SOC behaviours in their jobs show increased engagement at work. This is in line with previous research that indicates beneficial effects of SOC use at work for a variety of favourable individual outcomes (Abraham and Hansson 1995; Bajor and Baltes 2003; Demerouti et al. 2014; Müller et al. 2012; Weigl et al. 2013; Wiese et al. 2002; Yeung and Fung 2009; Zacher and Frese 2011). Specifically, applying strategies of 'successful aging' like setting priorities at work (selection), continuously improving job task execution (optimization), and balancing resources losses (compensation) is conducive to the physical and psychological capability of flight attendants to perform their work. With regard to the work engagement literature, our results indicate that individual life management strategies of successful aging are an important source for maintaining engagement on the job. This unique contribution of SOC behaviours is noteworthy since work engagement is an important motivational construct and a critical state for high psychological investment in performed work tasks (Christian et al. 2011). Thus, in jobs that impose age-sensitive demands upon employees, the effective application of SOC strategies supports employees in maintaining a physical, emotional, and cognitive involvement in their work.

Thirdly, our findings also emphasize the close relationship between contextual resources at work and SOC. Employees who reported higher job control also used significantly more SOC strategies in their jobs. This underlines previous investigations that showed a close association of positive job features, with a particular focus on job control, and SOC use 
Table 3 Results of mediation analyses of job resources (job control; learning and developmental opportunities) on work engagement through SOC strategy use

Job control-SOC-work engagement

(a) Direct effects

Job control on work engagement (H1)

SOC on work engagement (H2)

Job control on SOC (H3)

(b) Indirect effect

Job control on work engagement through SOC use (H4)

Model summary

Learning and developmental opportunities - SOC—work engagement

(a) Direct effects

Learning and developmental opportunities on work engagement (H1)

SOC on work engagement $(\mathrm{H} 2)$

Learning and developmental opportunities on SOC (H3)

(b) Indirect effect

Learning and development opportunities on work engagement through SOC use (H4)

Model summary

$B$

0.62

0.50

0.18

trapping $C I(95 \%)$

$\begin{array}{llll}B & S E & \text { Lower } & \text { Upper } \\ 0.09 & 0.08 & 0.02 & 0.22\end{array}$

$\mathrm{R}^{2}=0.19, \mathrm{~F}(\mathrm{df})=5.29(112), p<0.01$

\begin{tabular}{|c|c|c|c|}
\hline$B$ & $S E$ & $t$ & $p$ \\
\hline 0.52 & 0.13 & 4.12 & 0.01 \\
\hline 0.42 & 0.22 & 2.60 & 0.01 \\
\hline 0.21 & 0.06 & 3.11 & 0.01 \\
\hline \multicolumn{4}{|c|}{ Bootstrapping CI (95\%) } \\
\hline$B$ & $S E$ & Lower & Upper \\
\hline 0.09 & 0.05 & 0.02 & 0.22 \\
\hline
\end{tabular}

$N=118$; controlled for gender, age, and leadership position. Pooled estimates drawn from 10 imputed data sets. B 5,000 bootstrap samples at work (Müller et al. 2012, 2013b; Weigl et al. 2013). Our study contributes to the knowledge on the interplay between contextual resources and SOC in a two-fold way: First, we introduce a second job resource, which is distinct from job control: learning and developmental opportunities at work. Similar to job control, this vital contextual characteristic of the job environment was positively related to employees' SOC behaviours. Our results suggest that employees will benefit from organizations that establish work environments with opportunities for skill and knowledge development as well as for training and further education.

Our results are in line with previous attempts to consider the role of job resources for the development and effectiveness of SOC use. Earlier investigations assumed that SOC is helpful under demanding or stressful working conditions, because then SOC may be more effective in using available resources successfully (Young et al. 2007; Zacher and Frese 2011). The observed positive association between job control as well as learning and developmental opportunities and SOC suggests that the use of SOC on the job also requires favourable working conditions (Müller et al. 2012, 2013b). This finding supports assumptions that enhanced opportunities for skill acquisition and learning as well as high job control allow aging workers to better utilize and transfer their knowledge and work experience (Kanfer and Ackerman 2004). However, our findings call for further insights into the boundary conditions of the specific benefits of enhanced contextual resources for SOC use. For example, individual health problems or stress-related impairments may force employees to readapt and readjust their behavioural strate- gies for compensating specific losses in functioning (Müller et al. 2013a).

Overall, our findings corroborate the importance of favourable job design for successful aging at work, such as provision of opportunities for learning and skill development and establishing decision latitudes and time autonomy at work. Lastly, the confirmation of hypothesis 1 supports the vast evidence on the positive association of job resources and work engagement (Bakker and Demerouti 2007; Schaufeli and Bakker 2004). Hence, job control is a critical resource for functioning and well-being at work (e.g., de Lange et al. 2003; Terry and Jimmieson 1999).

\subsection{Limitations of the study}

Our study has several limitations that need to be considered. First and foremost, we applied a cross-sectional design, which limits the validity of causal inferences and increases the risk of circular reasoning. This refers particularly to our mediator model, which cannot be entirely confirmed using cross-sectional data. Hence, our findings allow only a preliminary evaluation of the hypothesized relationships. Although there is a sound theoretical basis for the suggested directions between the study variables, reciprocal effects cannot be ruled out. For example, aside from the assumed effect of SOC on work engagement, it is also possible that flight attendants with increased engagement at work are more energized and motivated to develop and utilize SOC behaviours; since the application of SOC strategies demands individual resources, e.g., vigour, persistence, and motivation (Freund 2006). Similarly, employees 
with enhanced contextual resources at work may engage in proactive behaviours and actively craft and extend their job resources (Weigl et al. 2010). Hence, future studies should apply longitudinal, cross-lagged panel designs that allow for testing reciprocal effects between study variables. Our sampling procedure is subject to various potentially biasing influences. The external validity of our sample thus is limited. We recruited a comparatively young sample of professionals and we cannot rule out cohort-specific effects. Due to our recruitment procedure we were not able to obtain information on non-responders. Thus, potential bias in key socio-demographic and work characteristic between participants and non-responders may have occurred. Moreover, selection bias may be present, such that flight attendants with lower work engagement and/or insufficient job resources did not take part in the study. Another potential selection effect that may have been occurred is the healthy worker effect, such that surveyed employees are more resilient to stress and strain at work, thus exhibiting increased levels of engagement ( $\mathrm{Li}$ and Sung 1999). Our data is based on a convenience sample, which may limit the generalizability of our results. For instance, online data collection may have ruled out employees with diminished access to email or intranet. With regard to the transfer of our results to other professions, we warrant caution since the work environment of flight attendants encompasses rather specific job demands and resources, which may limit the external validity of our findings.

Second, our study relied exclusively on self-reports. Hence, common method variance may lead to an inflation of observed associations (Podsakoff et al. 2003). However, there is support that common method itself produces limited systematic variance that may inflate correlational results to a significant degree (Spector 2006). Nonetheless, multimethod designs are suggested to rule out common method bias in SOC research, e.g., to include supervisor ratings for outcome variables or archival information for moderating variables (Weigl et al. 2013).

Third, although our hypothesized four factor measurement model was superior to alternative CFA models, the overall fit was only satisfactory (see Table 1 ). This replicates previous findings that reliabilities and factor distinctiveness of the original SOC scale as well as in connection with job related measures needs further psychometric development and revisions (Freund and Baltes 2002; Weigl et al. 2013).

Fourth, similar to previous investigations on the use of SOC strategies in work and organizational settings, we applied an overall measure of SOC strategies (Zacher and Frese 2011; Young et al. 2007; Bajor and Baltes 2003). Specifically, we used a composite SOC score that characterizes SOC strategies as a synchronized ensemble of action regulation behaviours (Baltes and Baltes 1990). This is in line with arguments that the adaptive capacity in aging indi- viduals is based on a set of control strategies or self-directed behaviours (Heckhausen et al. 2010; Lang et al. 2011). Nonetheless, we note that other studies have investigated single SOC strategies and their specific relationships with contextual factors or individual outcomes (Demerouti et al. 2014; Freund and Baltes 2002; Jop and Smith 2006). Since our aim was to examine the general effect of SOC strategies in flight attendants, we did not conduct analyses for separate SOC dimensions. However, we recommend further research to also investigate direct and indirect effects of single SOC components (Lang et al. 2011).

Lastly, we did not control for participants' general health status. Although work engagement is considered a component of psycho-physiological health (Christian et al. 2011; Schaufeli and Bakker 2004), the validity of our findings should also be tested for workers with limited health resources, i.e., chronic illness or mental disorders. Potentially, flight attendants with low health status may face problems or hindrances preventing the effective use of available job resources.

\subsection{Implications for research on successful aging at work} and work design practice

Beyond the implications for future research that derive from the limitations of this study, we see several starting points for future conceptualizations and investigations: Empirical evidence on the role and function of SOC strategies in the relationship between work characteristics and individual outcomes is still inconsistent. As discussed above, some studies postulate SOC strategies as a mediator while others argue for a moderating role. Future research should evaluate and combine competing theoretical and conceptual approaches and strive for empirical integration.

Further advances should draw on action theory (e.g., Frese and Zapf 1994; Hacker 2003), work design and job control theory (Hackman and Oldham 1976; Karasek 1979), and conservation of resources theory (Hobfoll 2001; Hobfol and Wells 1998), and also take account of life span models (Baltes and Dickson 2001; Baltes et al. 2012; Heckhausen et al. 2010).

Secondly, we need more research to address the boundary conditions when resources at work stimulate SOC use and under what circumstances contextual resources on the job can hinder SOC utilization. Several studies suggest that SOC-strategy use is particularly beneficial in complex work situations or when contextual resources at work are scarce (Schmitt et al. 2012; Yeung and Fung 2009; Zacher and Frese 2011). These results stem from the central assumption of the SOC model that SOC strategies are especially effective when individual and contextual resources are limited (Baltes and Baltes 1990). Complementary, our results show that enhanced job resources are related to increased 
SOC use. Hence, employees might be in a better position to use SOC strategies at work if they have sufficient latitude to make own work-related decisions and opportunities to obtain necessary skills and knowledge for improved resource allocation (Bajor and Baltes 2003; Müller et al. 2013b; Weigl et al. 2013). Thus, future research should investigate more rigorously, to what extent and which kind of contextual resources on the job limit and/or facilitate the development and application of SOC strategies.

Concerning practical implications, our study suggests that employees should be informed about the SOC model and trained in effective application of successful aging strategies at work (cf., Müller et al. 2013b). Such SOC trainings should address work-related applications of SOC behaviours to cope with individually relevant job demands. The development and implementation of such a training program requires active participation of employees, since the nature of individual resource allocation varies throughout the course of aging and across several occupational domains. Simultaneously, respective job design interventions need to supplement SOC effectiveness. Since learning and developmental opportunities as well as job control are conducive to SOC use, job re-design efforts should aim to enhance employee control and increase opportunities for individual learning and skill development. Our findings suggest that individual (person-oriented) and broad-based (conditionoriented) work design interventions can result in synergistic effects: enhanced resources at the job are directly conducive to enhanced engagement, and simultaneously stimulate enhanced use of life management strategies for successful aging, which in turn, promote engagement at work. Thus, SOC trainings could supplement and reinforce the effectiveness of job design interventions.

\section{Executive summary (German)}

- Handlungsstrategien der Selektion, Optimierung, und Kompensation (SOK) sind mitverantwortlich für die erfolgreiche Bewältigung von altersbedingten Veränderungen

- Arbeitsbedingungen können die Wirksamkeit von SOK Strategien am Arbeitsplatz beeinflussen

- Anhand einer Stichprobe von Flugbegleitern deutscher und österreichischer Fluggesellschaften konnten wir zeigen, dass Beschäftigte mit vermehrten SOK-Strategien auch mehr Arbeitsengagement erleben

- Flugbegleiter mit vermehrten Lern- und Entwicklungsmöglichkeiten sowie höherer Autonomie in der Arbeit, berichteten mehr SOK-Strategien sowie mehr Engagement in der Arbeit

- Unsere Ergebnisse zeigen, dass günstige Bedingungen in der Arbeit (sogenannte Arbeitsressourcen) entscheidend zur erfolgreichen Anwendung von alternsgünstigen Handlungsstrategien beitragen.

\section{References}

Abraham, J.D., Hansson, R.O.: Successful aging at work-an applied study of selection, optimization, and compensation through impression management. J. Gerontol. B. Psychol. Sci. Soc. Sci. 50(2), 94-103 (1995)

Anderson, J.C., Gerbing, D.W.: Structural equation modeling in practice - a review and recommended 2-step approach. Psychol. Bull. 103(3), 411-423 (1988)

Bajor, J.K., Baltes, B.B.: The relationship between selection optimization with compensation, conscientiousness, motivation, and performance. J. Vocat. Behav. 63, 347-367 (2003)

Bakker, A.B., Demerouti, E.: The job demands-resources model: state of the art. J. Manag. Psychol. 22(3), 309-328 (2007)

Baltes, B., Dickson, M.W.: Using life-span models in industrial-organizational psychology: the theory of selective optimization with compensation. Appl. Dev. Sci. 5(1), 51-62 (2001)

Baltes, B., Heydens-Gahir, H.A.: Reduction of work-family conflict through the use of selection, optimization, and compensation behaviors. J. Appl. Psychol. 88, 1005-1018 (2003)

Baltes, B., Rudolph, C.W., Bal, A.C.: A review of aging theories and modern work perspectives. The Oxford handbook of work and aging, pp. 117-136. Oxford University Press, Oxford (2012)

Baltes, M.M., Lang, F.R.: Everyday functioning and successful aging: the impact of resources. Psychol. Aging. 12(3), 433-443 (1997)

Baltes, P., Baltes, M.M.: Psychological perspectives on successful aging: the model of selective optimization with compensation. In: Baltes, P.B., Baltes, M.M. (eds.) Successful aging: Perspectives from the behavioral sciences, pp. 1-34. Cambridge University Press, New York (1990)

Baltes, P.B., Baltes, M.M., Freund, A.M., Lang, F.R.; Max Planck Institute for Human Development: The measure of selection, optimization, and compensation (SOC) by self-report. Max Planck Institute, Berlin (1999)

von Bonsdorff, M.E., von Bonsdorff, M.B., Zhou, Z.E., Kauppinen, M., Miettinen, M., Rantanen, T., Vanhala, S.: Organizational justice, selection, optimization with compensation, and nurses' work ability. J. Occup. Environ. Med. 56(3), 326-330 (2014)

Brown, T.A.: Confirmatory factor analysis for applied research. Guilford Press, New York (2006)

Byrne, B.M.: Structural equation modeling with AMOS. Lawrence Earlbaum Associates, Mahwah (2001)

Christian, M.S., Garza, A.S., Slaughter, J.E.: Work engagement: a quantitative review and test of its relations with task and contextual performance. Pers. Psychol. 64(1), 89-136 (2011)

Demerouti, E., Bakker, A.B., Nachreiner, F., Schaufeli, W.B.: The job demands-resources model of burnout. J. Appl. Psychol. 86(3), 499-512 (2001)

Demerouti, E., Bakker, A.B., Leiter, M.: Burnout and job performance: the moderating role of selection, optimization, and compensation strategies. J. Occup. Health Psychol. 19(1), 96-107 (2014)

van der Doef, M., Maes, S.: The job demand-control(-support) model and psychological well-being: a review of 20 years of empirical research. Work Stress. 13(2), 87-114 (1999)

Frese, M., Zapf, D.: Action as the core of work psychology: a German approach. In: Dunnette, M.D., Hough, L.M., Triandis, H.C. (eds.) Handbook of Industrial and Organizational Psychology, vol. 4, pp. 271-340. Consulting Psychologists Press, Palo Alto (1994) 
Freund, A.M.: Age-differential motivational consequences of optimization versus compensation focus in younger and older adults. Psychol. Aging. 21(2), 240-252 (2006)

Freund, A.M., Baltes, P.B.: Life-management strategies of selection, optimization and compensation: measurement by self-report and construct validity. J. Pers. Soc. Psychol. 82, 642-662 (2002)

Fried, Y., Ferris, G.R.: The validity of the job characteristics model: a review and meta-analysis. Pers. Psychol. 40(2), 287-322 (1987)

Grajewski, B., Nguyen, M.M., Whelan, E.A., Cole, R.J., Hein, M.J.: Measuring and identifying large-study metrics for circadian rhythm disruption in female flight attendants. Scand. J. Work Environ. Health. 29(5), 337-346 (2003)

Griffiths, R.F., Powell, D.M.: The occupational health and safety of flight attendants. Aviat. Space Environ. Med. 83(5), 514-521 (2012)

Hacker, W.: Action regulation theory: a practical tool for the design of modern work processes? Eur. J. Work Organ. Psychol. 12(2), 105-130 (2003)

Hackman, J.R., Oldham, G.R.: Motivation through the design of work: test of a theory. Organ. Behav. Hum. Perform. 16, 250-279 (1976)

Heckhausen, J., Wrosch, C., Schulz, R.: A motivational theory of lifespan development. Psychol. Rev. 117(1), 32-60 (2010)

Hobfoll, S.E.: The influence of culture, community, and the nested-self in the stress process: advancing conservation of resources theory. Appl. Psychol. 50(3), 337-370 (2001)

Hobfoll, S.E., Wells, J.D.: Conservation of resources, stress, and aging: why do some slide and some spring? In: Lomranz, J. (ed.) Handbook of Aging and Mental Health: An Integrative Approach. pp. 121-134. Plenum Press, New York (1998)

Humphrey, S.E., Nahrgang, J.D., Morgeson, F.P.: Integrating motivational, social, and contextual work design features: a meta-analytic of the summary and theoretical extension work design literature. J. Appl. Psychol. 92(5), 1332-1356 (2007)

Jopp, D., Smith, J.: Resources and life-management strategies as determinants of successful aging: on the protective effect of selection, optimization, and compensation. Psychol. Aging. 21(2), 253-265 (2006)

Kanfer, R., Ackerman, P.L.: Aging, adult development, and work motivation. Acad. Manage. Rev. 29(3), 440-458 (2004)

Karasek, R.A.: Job demands, job decision latitude and mental strain: implications for job redesign. Adm. Sci. Q. 24, 285-306 (1979)

Lang, F.R., Rohr, M., Williger, B.: Modeling success in life-span psychology: the principles of selection, optimization, and compensation. In: Fingerman, K.L., Berg, C., Smith, J., Antonucci, T.C. (eds.) Handbook of Life-Span Development. pp. 57-85. Springer, New York (2011)

de Lange, A.H., Taris, T.W., Kompier, M.A., Houtman, I.L., Bongers, P.M.: "The very best of the millennium": longitudinal research and the demand-control-(support) model. J. Occup. Health Psychol. 8(4), 282-305 (2003)

Lerner, R.M., Overton, W.F.: The Handbook of Life-Span Development : Cognition, Biology, and Methods, (vol. 1). Wiley, Hoboken (2010)

Li, C.Y., Sung, F.C.: A review of the healthy worker effect in occupational epidemiology. Occup. Med. (Lond) 49(4), 225-229 (1999)

Maurer, T.J.: Career-relevant learning and development, worker age, and beliefs about self-efficacy for development. J. Manage. 27(2), 123-140 (2001)

Morgeson, F.P., Humphrey, S.E.: The work design questionnaire (WDQ): developing and validating a comprehensive measure for assessing job design and the nature of work. J. Appl. Psychol. 91(6), 1321-1339 (2006)

Müller, A., Weigl, M., Heiden, B., Glaser, J., Angerer, P.: Promoting work ability and well-being in hospital nursing: the interplay of age, job control, and successful ageing strategies. Work. 41, 5137$5144(2012)$
Müller, A., de Lange, A., Weigl, M., Oxfart, C., van der Heijden, B.: Compensating losses in bridge employment? Examining relations between compensation strategies, health problems, and intention to remain at work. J. Vocat. Behav. 83(1), 68-77 (2013a)

Müller, A., Heiden, B., Weigl, M., Glaser, J., Angerer, P.: Successful aging strategies in nursing: the example of selective optimization with compensation. In: Schlick, C.M., Frieling, E., Wegge, J. (eds.) Age-differentiated work systems. pp. 175-199. Springer, Heidelberg (2013b)

Podsakoff, P.M., MacKenzie, S.B., Lee, J.Y., Podsakoff, N.P.: Common method biases in behavioral research: a critical review of the literature and recommended remedies. J. Appl. Psychol. 88(5), 879-903 (2003)

Preacher, K.J., Hayes, A.F.: Asymptotic and resampling strategies for assessing and comparing indirect effects in multiple mediator models. Behav. Res. Methods. 40(3), 879-891 (2008)

Preacher, K.J., Rucker, D.D., Hayes, A.F.: Addressing moderated mediation hypotheses: theory, methods, and prescriptions. Multivar. Behav. Res. 42(1), 185-227 (2007)

Riediger, M., Li, S.-C., Lindenberger, U.: Selection, optimization, and compensation as developmental mechanisms of adaptive resource allocation: review and preview. In: Birren, J.E., Schaie, K.W. (eds.) Handbook of the Psychology of Aging. 6th edn, pp. 289 314. Elsevier, Amsterdam (2006)

Rubin, D.B.: Multiple Imputation for Nonresponse in Surveys. Wiley, New York (1987)

Saavedra, R., Kwun, S.K.: Affective states in job characteristics theory. J. Organ. Behav. 21, 131-146 (2000)

Schafer, J.L., Graham, J.W.: Missing data: our view of the state of the art. Psychol. Methods. 7(2), 147-177 (2002)

Schaie, K.W., Willis, S.L. (eds.): Handbook of the Psychology of Aging. Elsevier Academic Press, San Diego (2010)

Schaufeli, W.B., Bakker, A.B.: The Utrecht Work Engagement Scale (UWES): test manual. Utrecht University, Department of Social and Organizational Psychology, Utrecht, (2003)

Schaufeli, W.B., Bakker, A.B.: Job demands, job resources, and their relationship with burnout and engagement: a multi-sample study. J. Organ. Behav. 25(3), 293-315 (2004)

Schmitt, A., Zacher, H., Frese, M.: The buffering effect of selection, optimization, and compensation strategy use on the relationship between problem solving demands and occupational well-being: a daily diary study. J. Occup. Health Psychol. 17(2), 139-149 (2012)

Shrout, P.E., Bolger, N.: Mediation in experimental and nonexperimental studies: new procedures and recommendations. Psychol. Methods. 7(4), 422-445 (2002)

Shultz, K.S., Adams, G.A.: Aging and Work in the 21st Century. Lawrence Erlbaum., Mahwah (2007)

Sonntag, K., Stegmaier, R.: Das Lernkulturinventar (LKI)-Ermittlung von Lernkulturen in Wirtschaft und Verwaltung. In: Fisch, R., Müller, A., Beck, D. (eds.) Veränderungen in Organisationen, pp. 227-247. VS Verlag für Sozialwissenschaften, Wiesbaden (2008)

Spector, P.E.: Method variance in organizational research truth or urban legend? Organ. Res. Methods. 9(2), 221-232 (2006)

Stegmann, S., Dick, R.v., Ullrich, J., Charalambous, J., Menzel, B., Egold, N., Wu, T.T.-C.: Der Work Design Questionnaire. Zeitschrift für Arbeits- und Organisationspsychologie AO. 54(1), 1-28 (2010)

Terry, D.J., Jimmieson, N.L.: Work control and employee well-being: a decade review. In: Cooper, C.L., Robertson, I.T. (eds.) International Review of Industrial and Organizational Psychology. Wiley, Chichester (1999)

Wall, T.D., Jackson, P.R., Mullarkey, S.: Further evidence on some new measures of job control, cognitive demand and production responsibility. J. Organ. Behav. 16(5), 431-455 (1995) 
Weigl, M., Hornung, S., Parker, S.K., Petru, R., Glaser, J., Angerer, P.: Work engagement and accumulation of task, social, personal resources: a three-wave structural equation model. J. Vocat. Behav. 77(1), 140-153 (2010)

Weigl, M., Müller, A., Hornung, S., Zacher, H., Angerer, P.: The moderating effects of job control and selection, optimization, and compensation strategies on the age-work ability relationship. J. Organ. Behav. 34(5), 607-628 (2013)

Wiese, B.S., Freund, A.M., Baltes, P.B.: Subjective career success and emotional well-being: longitudinal predictive power of selection, optimization and compensation. J. Vocat. Behav. 60, 321-335 (2002)

Yeung, D.Y., Fung, H.H.: Aging and work: how do soc strategies contribute to job performance across adulthood? Psychol. Aging. 24(4), 927-940 (2009)

Young, L.M., Baltes, B.B., Pratt, A.K.: Using selection, optimization, and compensation to reduce job/family stressors: effective when it matters. J. Bus. Psychol. 21, 511-539 (2007)

Zacher, H., Frese, M.: Maintaining a focus on opportunities at work: the interplay between age, job complexity, and the use of selection, optimization, and compensation strategies. J. Organ. Behav. 32(2), 291-318 (2011)

Zacher, H., Heusner, S., Schmitz, M., Zwierzanska, M.M., Frese, M.: Focus on opportunities as a mediator of the relationships between age, job complexity, and work performance. J. Vocat. Behav. 76(3), 374-386 (2010)
Matthias Weigl, is a researcher in industrial and organizational psychology at the Institute and Outpatient Clinic for Occupational, Social, and Environmental Medicine of Munich University, Germany. His research interests are in the areas of work design, employee wellbeing, performance, and quality in health care organizations.

Andreas Müller, is a researcher in industrial and organizational psychology at the Institute for Occupational and Social Medicine of Düsseldorf University, Germany. His research interests include work and organizational design in industrial and health care jobs, successful aging at work, and employee well-being, and health.

Severin Hornung, is scientific researcher at the Institute for Psychology, Leopold-Franzens-University, Innsbruck, Austria. His research focuses on idiosyncratic deals, the psychological employment relationship, flexibility in HR-practices, and proactive behavior.

Max Leidenberger, graduated in 2013 from the Institute for Psychology, Leopold-Franzens-University, Innsbruck, Austria. His research includes employee health and motivation.

Barbara Heiden, is a physician at the Institute and Outpatient Clinic for Occupational, Social, and Environmental Medicine, Medical Faculty, Ludwig-Maximilians-University, Munich, Germany. Her research interests are in the field of psychosocial risk assessment, successful ageing, and employee health. 